CASE REPORT

\title{
Very late thrombosis after implantation of sirolimus eluting stent
}

\author{
E Karvouni, S Korovesis, D G Katritsis
}

Heart 2005;91:e45 (http://www.heartjnl.com/cgi/content/full/91/6/e45). doi: 10.1136/hrt.2004.056341

Stent thrombosis after sirolimus eluting stent implantation has been reported to occur at six hours to 375 days after the procedure and usually within the two weeks after discontinuation of antiplatelet medication. A case is reported of very late stent thrombosis after 17 months of sirolimus eluting stent implantation and eight months after clopidogrel discontinuation despite aspirin continuation. This case underlines the possible need for long term antiplatelet medication among patients receiving sirolimus eluting stents.

$\mathrm{S}$ tent thrombosis after sirolimus eluting stent (SES) implantation has been reported to range between 0.4 $1 \% .^{1{ }^{2}}$ The first reported cases have been documented at six hours to six weeks after the procedure, ${ }^{1-3}$ although late thrombosis as late as $\mathbf{3 7 5}$ days after SES implantation has recently been reported. ${ }^{4}$

The discontinuation of antiplatelet medication has been strongly associated with SES thrombosis that is usually seen within the two weeks after cessation of treatment. ${ }^{1-3}$ The optimal duration of clopidogrel administration in this clinical setting has not been established.

We report on a case of very late stent thrombosis 17 months after SES implantation and eight months after clopidogrel discontinuation despite aspirin continuation. Until data from randomised trials address this issue, this case underlines the possible need for long term antiplatelet medication including clopidogrel in patients receiving SES.

\section{CASE REPORT}

A 44 year old male smoker with arterial hypertension and diabetes mellitus was referred for coronary angiography after a recent anterior myocardial infarction and evidence of myocardial ischaemia. Coronary angiography showed a significant lesion in the mid-segment of the left anterior descending coronary artery (LAD) and total occlusion of the large first diagonal branch (fig 1A). Primary stenting of the LAD lesion was undertaken with implantation of two overlapping Cypher (Cordis Corp, Johnson \& Johnson, Warren, New Jersey, USA) stents $(3.0 \times 8 \mathrm{~mm}$ and $2.75 \times 8 \mathrm{~mm}$ at $14 \mathrm{~atm})$ and an excellent angiographic result (fig 1B). Subsequent fractional flow reserve evaluation verified the absence of any haemodynamically significant residual stenosis (fractional flow reserve of 0.92). Balloon angioplasty with a $2.5 \times 15 \mathrm{~mm}$ Maverick balloon (Boston Scientific) inflated at 12 atm was performed in the diagonal branch (fig 1B). The patient was preloaded with $300 \mathrm{mg}$ of clopidogrel orally and during the procedure intravenous eptifibatide and enoxaparin $(1 \mathrm{mg} / \mathrm{kg})$ were administered. The procedure was uneventful and the patient was prescribed aspirin $100 \mathrm{mg}$ and clopidogrel $75 \mathrm{mg}$ orally daily for one year. He remained asymptomatic and discontinued his clopidogrel nine months after the procedure, continuing only with aspirin, statin, and $\beta$ blockade. Eight months later he developed acute chest pain and his resting ECG showed ST elevation $>1 \mathrm{~mm}$ in leads $\mathrm{V} 2-\mathrm{V} 6$. He received thrombolysis and was referred for angiography the same day. In-stent thrombosis was shown at the entrance of the proximal Cypher stent in the LAD lesion (fig $1 C$ ). No restenosis was
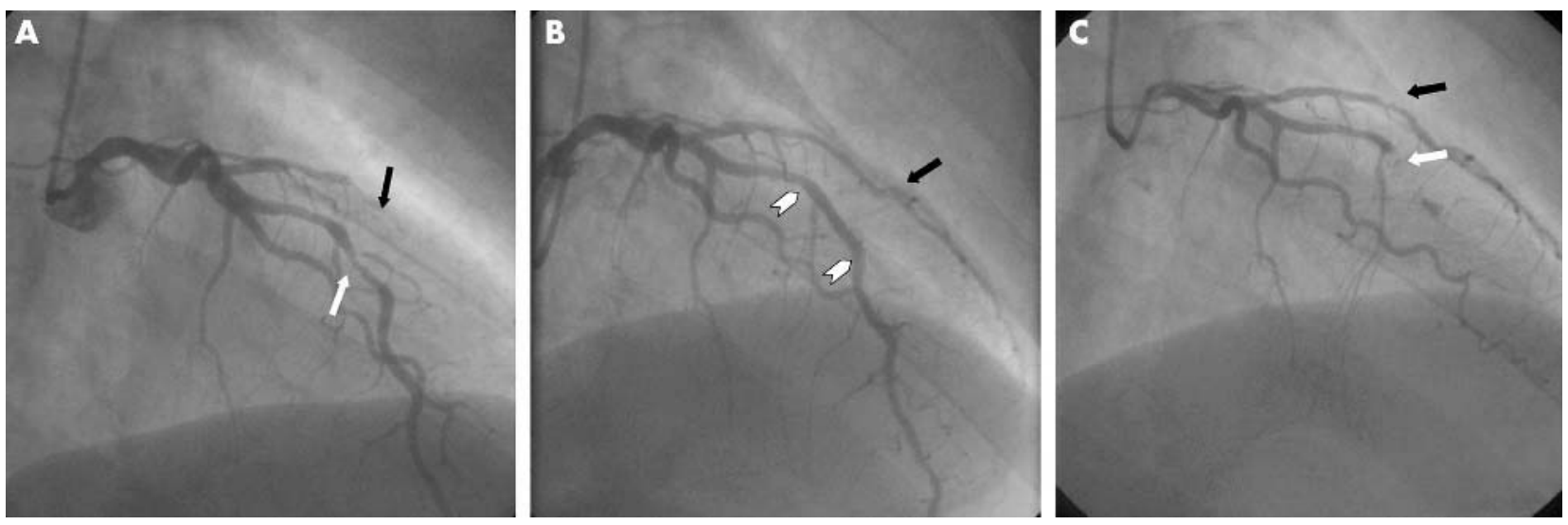

Figure 1 (A) Baseline coronary angiography showing significant lesion in the mid segment of left anterior descending coronary artery (LAD; black arrow) and total occlusion of the first diagonal branch (white arrow). (B) Postprocedural coronary angiography after direct stenting in the mid segment of LAD with two overlapping Cypher stents (arrowheads) and balloon angioplasty in the first diagonal branch (black arrow). (C) Coronary angiography 17 months after the procedure showing total occlusion at the proximal edge of the proximal Cypher stent implanted in the mid segment of the LAD (white arrow) and no restenosis in the first diagonal branch (black arrow). 
detected in his diagonal branch (fig 1C). Platelet count and coagulation profile were unremarkable. He was treated with a repeat procedure and three months later he remains asymptomatic.

\section{DISCUSSION}

To the best of our knowledge this is the most delayed case of SES thrombosis, occurring more than a year after stent implantation and eight months after discontinuation of clopidogrel despite aspirin continuation. Late stent thrombosis after implantation of sirolimus and paclitaxel eluting stents has been reported up to 375 and 442 days, respectively, after the procedure. ${ }^{4}$ In the series of Jeremias et al, ${ }^{1}$ stent thrombosis was noted early (four and nine days) after discontinuation of clopidogrel and aspirin. In the most recent published cases of stent thrombosis after SES or paclitaxel eluting stent, all cases of stent thrombosis occurred a few days after aspirin discontinuation and days or months after clopidogrel discontinuation. ${ }^{4}$ Although in these cases stent thrombosis seems to have been more closely related to aspirin discontinuation, the time window for thrombosis after clopidogrel discontinuation is not well defined. Our case underlines this issue, since stent thrombosis occurred eight months after clopidogrel discontinuation although the patient continued to take aspirin.

There have been early concerns about delayed healing and polymer related hypersensitivity reactions, with consequent risks of delayed thrombosis after drug eluting stent implantation. ${ }^{56}$ Sirolimus and paclitaxel effectively reduce restenosis by inhibiting neointimal hyperplasia, but they also delay the healing process far beyond the 3-6 month period usually required with bare metal stents. ${ }^{56}$ Impaired intimal healing is a recognised cause of late stent thrombosis in humans. ${ }^{7}$ Furthermore, polymer coatings used in commercially available drug eluting stents as reservoirs of medications may result in major intimal inflammation. ${ }^{8}$ Pathology studies have provided evidence of hypersensitivity vasculitis within the stented arterial segment after SES implantation with polymer fragments surrounded by giant cells and eosinophils. ${ }^{8}$

Local factors such as flow limiting dissections and areas of low flow, as well as presence of adjacent vulnerable plaques, have been identified as independent predictors of stent thrombosis. ${ }^{10}$ In our patient, there was a non-significant disease in the arterial segment immediately proximal to the stented area angiographically. In addition, post-stenting fractional flow reserve excluded any possible haemodynamically significant stenosis, and at repeat angiography there was no obvious angiographic deterioration of the proximal non-significant stenosis.

In conclusion, our case report presents evidence of very late stent thrombosis with the use of SES and argues in favour of prolonged antiplatelet medication including clopidogrel in this setting, at least until data from randomised trials address this important issue.

\section{Authors' affiliations \\ E Karvouni, S Korovesis, D G Katritsis, Athens Euroclinic, Athens, Greece}

Correspondence to: Dr D Katritsis, Athens Euroclinic, 9 Athanassiadou Street, 11521 Athens, Greece; dkatritsis@euroclinic.gr

Accepted 29 November 2004

\section{REFERENCES}

1 Jeremias A, Sylvia B, Bridges J, et al. Stent thrombosis after successful sirolimus-eluting stent implantation. Circulation 2004;109:1930-2.

2 Regar E, Lemos PA, Saia F, et al. Incidence of thrombotic stent occlusion during the first three months after sirolimus-eluting stent implantation in 500 consecutive patients. Am J Cardiol 2004;93:1271-5.

3 Kerner A, Gruberg L, Kapeliovich M, et al. Late stent thrombosis after implantation of a sirolimus-eluting stent. Catheter Cardiovasc Interv 2003:60:505-8.

4 McFadden EP, Stabile E, Regar E, et al. Late thrombosis in drug-eluting coronary stents after discontinuation of antiplatelet therapy. Lancet 2004;364:1519-21

5 Virmani R, Guagliumi G, Farb A, et al. Localized hypersensitivity and late coronary thrombosis secondary to a sirolimus-eluting stent: should we be cautious? Circulation 2004; 109:r8-r42.

6 Virmani R, Liistro F, Stankovic G, et al. Mechanism of late in-stent restenosis after implantation of a paclitaxel derivate-eluting polymer stent system in humans. Circulation 2002;106:2649-51.

7 Farb A, Burke AP, Kolodgie FD, et al. Pathological mechanisms of fatal late coronary stent thrombosis in humans. Circulation 2003;108:1701-6.

8 Van der Giessen WJ, Lincoff AM, Schwartz RS, et al. Marked inflammatory sequelae to implantation of biodegradable and nonbiodegradable polymers in porcine coronary arteries. Circulation 1996;94:1690-7.

9 Wang F, Stouffer GA, Waxman S, et al. Late coronary stent thrombosis: early vs. late stent thrombosis in the stent era. Catheter Cardiovasc Interv 2002; 55: 142-7.

10 Cutlip DE, Baim DS, Ho KK, et al. Stent thrombosis in the modern era: a pooled analysis of multicenter coronary stent clinical trials. Circulation 2001;103:1967-71. 